Hughes, W.F., Mattimore, J.M. \& Arbesman, C.E. (1969) Farmer's lung in an adolescent boy. American Journal of Diseases in Childhood, 118, 777.

Pepys, J. \& Jenkins, P.A. (1965) Precipitin (FLH) test in farmer's lung. Thorax, 20, 21.
Rankin, J., Jaeschke, W.H., Callies, Q.C. \& Dickie, H.A. (1962) Farmer's lung. Annals of Internal Medicine, 57, 606.

SPAIN, D.M. \& VAN Wormer, D.E. (1965) Farmer's lung. Archives of Environmental Health, 10, 71.

\title{
Female genital self-mutilation as a cause of vaginal bleeding
}

\author{
M. A. SimpSON \\ M.B.B.S., L.R.C.P., M.R.C.S., D.P.M. \\ B. H. AnSTEE* \\ M.A., M.B., B.Chir., M.R.C.Psych., D.Obst., \\ R.C.O.G., D.P.M.
}

\begin{abstract}
Summary
While self-mutilation in the form of wrist and arm cutting is relatively common and genital self-mutilation in men is well recognized, female genital selfmutilation seems to be strikingly rare. With the exception of injuries secondary to frank self-induced abortion or the insertions of foreign bodies in children, only three cases of female genital self-mutilation have been reported in the literature so far. It is suggested that the phenomenon may not be as rare as hitherto supposed and therefore a further case is reported.
\end{abstract}

\section{Case report}

Mary D., 22, was born as the result of an unwanted and fiercely resented pregnancy. Her mother, who had regarded sex as abhorrent and unnecessary, became frigid from that time. She was an isolated, unhappy child who commonly feigned illness to avoid going to school. The day after starting work on leaving school, she began to complain of abdominal pain, inter-menstrual bleeding and heavy periods, and commenced a series of hospital admissions for investigation, including and appendicectomy at which the finding was 'mesenteric adenitis'. She made several attempts to start nursing training, but was not accepted. During this time she accepted her boyfriend's persistent persuasion and had sexual intercourse once. Subsequently she became frightened that she might be pregnant and introduced a knitting needle per vaginam producing some bleeding which resulted in a hospital admission and a dilatation and curettage which was followed by her first episode of wrist cutting, and the first or numerous admissions to psychiatric hospitals.

\footnotetext{
*Present address: The Old Manor Hospital, Salisbury, Wilts.
}

Later, admitted to another London teaching hospital for investigation of her abdominal symptoms, she began to behave in a more overtly disturbed fashion and it was suspected that her pyrexia, vomiting and other symptoms were self-induced. She tore open the wound from her lymphangiogram which became infected. While being seen as an out patient, she arrived at another teaching hospital's? casualty department having inflicted a deep laceration on her left breast and with a twig in her vagina which needed removal. She told the police she had been attacked in a car park, but withdrew her story before an identity parade was to be held. There followed a series of admissions to various hospitals with episodes of wrist cutting, swallowing metal objects and introducing small metal objects into her vagina. There were over a dozen separate incidents of self-mutilation responding poorly to a variety of treatments.

Then at the beginning of 1972 she was admitted to the local hospital following vaginal cuts producing sufficiently profuse bleeding to need transfusion. Two months later she arrived in our casualty department having lacerated her vulva and vagina with a knitting needle and a kitchen knife. The lacerations were repaired but on the gynaecology ward she smashed a window and cut her arm, and was transferred to a psychiatric ward. She had ten ECTs without much benefit and displayed a great deal of actingout behaviour including public and easily restrained attempts to mutilate herself. She inserted a sewing needle and on another occasion a knitting needle into her vagina. She told a nurse and then demanded to be allowed to discharge herself immediately. After the second such incident she was allowed to leave. 
Several months later, she arrived in casualty again having cut her vagina with scissors on the previous day, sustaining multiple superficial lacerations of the vagina and cervix. She was admitted for observation and after 4 days discharged herself again refusing offers of further help.

\section{Comment}

Her self-mutilating behaviour shares several features with the typical wrist cutters. She plans each incident carefully enjoying the anticipation of the event. She feels no pain when cutting and feels relief and fascination watching her blood flow. Even her major vaginal lacerations were painless for a period of some $24 \mathrm{hr}$.

The case described by Goldfield and Glick (1970) was a girl of 19 who scratched and gorged her internal genitalia with her finger-nails, leading to prolonged investigation of vaginal bleeding for which she received three dilatation and curettages, a cervical conization and multiple cauterizations, and was pleading for a hysterectomy. Gerstle, Guttmacher and Brown's (1957) case was regarded as one of malingered placenta praevia. The patient mutilated her vagina with a hatpin or knitting needle in late pregnancy on four occasions, producing enough bleeding to justify a caesarean section on the grounds of presumed placenta praevia. French and Nelson's (1972) case lacerated her vulva superficially with a razor blade on one occasion.

The first case sought multiple gynaecological procedures and wanted a hysterectomy, her disturbance starting after the birth of an illegitimate child. The second case gained delivery by caesarean section of a pregnancy she found unbearable and our patient started her mutilations when fearing pregnancy, and succeeded in gaining a reassuring dilatation and curettage.

It is an open question whether similar episodes of self-mutilation when less exaggerated and bizarre, may not be more common than is usually supposed, and may pass unnoticed and indeed succeed in inducing the various gynaecological procedures the patients may be seeking.

\section{References}

French, A.P. \& Nelson, H.L. (1972) Genital self-mutilation in women. Archives of General Psychiatry, 27, 618.

Gersble, M.L., Guttmacher, A.F. \& Brown, F. (1957) A case of recurrent malingered placenta praevia. Journal of Mount Sinai Hospital, 24, 641.

GoldFIELD, M.D. \& GLICK, I.R. (1970) Self-mutilation of the female genitalia: a case report. Diseases of the Nervous System, 31, 843.

\title{
The syndrome of dilutional hyponatremia
}

\author{
D. P. MisRa \\ B.Sc., M.B., M.R.C.P. \\ Department of Geriatric Medicine, Bristol General Hospital
}

\begin{abstract}
Summary
Three cases of dilutional hyponatremia are presented. All had ADH bio-assay at the height of biochemical abnormality and the values were found to be normal. The first two cases were due to cortisol deficiency. An interesting feature of these two cases was a high exchangeable sodium which was corrected by administration of cortisone, suggesting that cortisol plays some part in the distribution of sodium between the extracellular and the intracellular space. The third case occurred in association with urinary tract infection. Similar findings have been reported in elderly patients with pneumonia and have been presumed to be due to inappropriate secretion of ADH on indirect evidence. ADH assay has rarely been done and has never been found to be high. On the basis of the findings observed in the three cases, it is suggested that factors other than ADH excess and cortisol deficiency are involved in the production of dilutional hyponatremia.
\end{abstract}

\section{Introduction}

Hyponatremia associated with fluid retention and expansion of body fluid presents a complex problem. The diagnosis is based on low plasma sodium, low plasma osmolarity, a high extracellular fluid (ECF) volume or plasma volume, a low or low normal plasma urea and absence of clinical oedema. This syndrome has been described in various disorders, namely, carcinoma of bronchus, pneumonia, tuberculosis of lungs, encephalitis, meningitis and postoperative states. The underlying cause in these cases has usually been attributed to abnormal antidiuretic hormone (ADH) production.

Schwartz et al. (1957) described this syndrome in two cases of bronchogenic carcinoma and proposed that inappropriate secretion of ADH was responsible. Lee, Jones and Barraclough (1964) lent support to the above hypothesis. They assayed ADH levels in urine, blood and tumour tissue and found the level 